\title{
Virtual Reality-Based Training: Case Study in Mechatronics
}

\section{Dorota Kamińska ${ }^{1}$ (D) - Grzegorz Zwoliński ${ }^{1}$ S Sławomir Wiak ${ }^{1}$ - Lidija Petkovska ${ }^{2}$. Goga Cvetkovski ${ }^{2}$ Paolo Di Barba ${ }^{3} \cdot$ Maria Evelina Mognaschi $^{3} \cdot$ Rain Eric Haamer $^{4}$. Gholamreza Anbarjafari ${ }^{4,5}$}

Published online: 25 August 2020

(c) The Author(s) 2020

\begin{abstract}
This paper introduces, explains and illustrates real-life application of virtual training tool for electrical engineering education. The tool gives users the opportunity to interact with and manipulate $3 \mathrm{D}$ models of authentic devices. The users have a possibility to compare structural differences between devices, assemble and disassemble the machines and test them under extreme conditions, all of which would not be possible while working with a real device. The 3D devices are fully operational allowing the users to interact with them on every level, including analysis of impact of supply conditions i.e. modify voltage and frequency of a particular motor and monitor changes in performance while still operating. The main goal of this research was to evaluate effectiveness and educational values of the proposed tool. Early studies and feedback from educators and students prove this tool to be a great assistance to process of education, facilitating knowledge acquisition and providing an innovative way to put theory into practice.
\end{abstract}

Keywords Virtual reality $\cdot$ Education $\cdot$ Human-computer interface $\cdot$ Teaching/learning Strategies

\section{Introduction}

Difficulties of students of science-related subjects often stem from the abstractness and complexity of learned concepts and the fact that those concepts process are not easily applied in practice. Lack of understanding of fundamentals stifles their potential growth and development and exploration of more complicated issues. Specialized equipment

Dorota Kamińska

dorota.kaminska@p.lodz.pl

1 Institute of Mechatronics and Information Systems, Lodz University of Technology, Łódź, Poland

2 Faculty of Electrical Engineering and Information Technologies, Ss. Cyril and Methodius University, Skopje, Macedonia

3 Department of Electrical, Computer and Biomedical Engineering, University of Pavia, Pavia, Italy

4 Tartu Ulikool, Tartu, Estonia

5 Department of Electrical and Electronic Engineering, Hasan Kalyoncu University, Gaziantep, Turkey 
used for practical exercises is expensive, thus students are under close scrutiny when conducting any activity using the devices. They are not allowed to experiment with the device itself, experience emergency states or the effects of misconfiguration, as it may lead to equipment damage and is often against every health and safety regulation implemented in the facility. Such conditions of work also prevent them from working on their own, practicing and catching up outside the laboratory schedule. There are some ways to mitigate this problem and very often they are connected with utilizing technologies such as online courses, blended learning, different computer based platforms and other solutions that allow the students to revise the knowledge on demand and make mistakes without any consequences. The Ed-tech industry can improve education results for most students as various examples of hardware and software solutions implemented into the education process indicate (Nadan et al. 2011).

Technology-based tools are finding their way to more and more educational centers all over the world. Paper books are being replaced by digital instructional content from open educational resources, notebooks are being pushed out by laptops, tablets or mobile phones, analogue blackboards are giving way to interactive whiteboards and, most significantly, standardized education process is being transformed into more personalized learning opportunities tailored to each individual student's academic strengths, weaknesses, preference, and goals (Courts and Tucker 2012).

The use of information and communication technologies has been proven to boost students' results or their attitude towards learning. With its continuous development and research growth, the potential of ed-tech is still uncapped.Over the last several years, virtual reality (VR) has moved from being the purview of gaming to application in professional development such as psychology, medicine as well as education. The application in the learning process is of special interest, as it gives completely new opportunities to provide information and acquire both theoretical and practical knowledge. Some of the benefits of VR application in fields of education have already been examined. Not only does it serve as a hook (Zavalani and Spahiu 2012), but it can also improve morale of participating students (Sulbaran and Baker 2000). Virtual reality changes completely the way the users interact with the device, it gives them freedom to experiment and come up with bold, innovative applications or prototypes without worrying about damaging expensive equipment (Makarova et al. 2015). The relative inexpensiveness of modern virtual headsets (Hurtado et al. 2010) provides even small-budget teaching institutions with the ability to carry out proper practical education, otherwise unavailable to them.

The main focus of this paper is ViMeLa project (Cvetkovski et al. 2019), a state-of-theart tool for both teachers and students of mechatronics. The concept utilizes a blendedlearning approach that combines traditional on-premises classroom methods with virtual reality as an experimentation tool. Here, specifically, it is a hybrid approach that incorporates digital media through VR into a traditional place-based learning process and is more effective in teaching mechatronics compared with traditional face-to-face methods. Virtual worlds are very easily modifiable, adaptable and can replace expensive realia without the loss of any of their advantages, at the same time providing many more opportunities of operation. The innovation of the presented tool lies in developing an original and novel electric motor training system based on VR technology. The users can observe and explore a digital, fully interactive environment created specifically for this project and dynamically change it to cater for all the needs and tasks.

The structure of the paper is the following. The next section explores VR capabilities and briefly reviews the related works. Section 3 provides details of the project: scenario, 
the training application and testing method. Finally, Sect. 4 presents obtained results, lessons learned, conclusion and potential future development of the tool in question.

\section{Related Works}

\subsection{Virtual Reality}

Humans have been always looking for different channels for fueling their creativity such as reverie or entering altered states of consciousness by various means. With the development of technology, products enabling transfer of human senses into the programmable experience space have been created. An example of such a product is virtual reality (VR). The simplest forms may be limited to just the stimulation of sight and hearing, making it relatively easy to achieve. Thus the most basic VR system may be comprised of a monitor with a set of speakers. However, due to the intensive development of headmounted displays (HMD), such solutions have been devalued so much that they are no longer classified as VR. With panoramic displays and a number of built-in motion tracking sensors, the user may even experience fictive environments, which replicate the real world in its appearance and physical phenomena.

There are a lot of peripheral components accompanying HMD: starting from overload stimulation in the form of various mechanical and motor constructions (e.g. treadmills) (Mirelman et al. 2016) to direct haptic solutions (e.g. mapping of the texture of touching object) (Park 2019; Kreimeier et al. 2019) and indirect (e.g. wind, heat, snow, rain etc.) (Chapman et al. 2019; Suzuki and Matsuura 2019). In addition to the motion tracking sensors, eye tracking solutions (e.g. behavioral analysis, dedicated scene rendering) (Wechsler et al. 2019), biochemical parameters (e.g. stress detection) or EEG signals capture (e.g. assisting people with mobility limitations) (Qidwai et al. 2019) as well as stimulation and detection of magnetic disorders (e.g. research into the sixth sense) (Servick 2019; Wang et al. 2019) can be used to monitor the experience.

\subsection{Virtual Reality in Engineering Education}

Nowadays, engineering training is widely conducted by utilizing simulators and virtual reality technology. Ability to make early in-design decisions in a cost effective manner is a feature that greatly contributed to the popularity and attractiveness of VR solutions in this field (Pantelidis 1997). Additional benefits include a better understanding of intricacies of the design, facilitating any necessary adjustments and reducing or mitigating the time and cost factor, which haunt many modern design processes (Gandhi and Patel 2018). In this section several state-of-the-art applications will be described briefly.

A very good example is Virtual Labs (Achuthan et al. 2011) (Government of India Initiative), which provides remote access to the laboratories of various disciplines of science and engineering. Students of Indian universities can access relevant tools for learning, including web-resources, video-lectures, animated demonstrations and self evaluation. Such tools allow to gain only theoretical knowledge on a particular subject, while the practical part is completely omitted, thus not allowing students to acquire real experience. Another good example is MARVEL project (Müller and Ferreira 2003). MARVEL is a virtual learning environment for mechatronics training in which students 
are provided online access to physical workshops and laboratory facilities from remote places and learning venues. However, both above-mentioned platforms do not use VR technology based on Head Mounted Display (HMD), utilizing only computers and the Internet.

Dinis et al. Dinis et al. (2017a) give an overview of VR and AR applications for civil engineering education utilizing gamification elements. The aim of the project was to introduce tools that would engage users in a way which is more familiar to them because of their age, motivate them by including gaming elements and at the same time transfer knowledge and practical skills necessary for their future careers. However, the main goal of the project might be summarized as explaining and defining the role of civil engineering to K-12 students and its relevance to the community. In their accompanying research (Dinis et al. 2017b), a VR platform was developed as a vehicle to educate even younger students on civil engineering. The results were highly promising and support the idea of using VR as a tool in Civil Engineering Education, as it enables users without formalized knowledge or training to properly interact with the platform.

Another example of using VR in civil engineering is provided by Sampio et al. Sampaio and Martins (2017). The authors set out to produce interactive 3D models to give users deeper insight into the structure of roofs, walls and a bridge. These scenarios were accompanied by relevant simulations of their construction and the interaction with the models enabled the users to monitor the process of development and gain valuable practical information about each element.

Electrical engineering education has also been reinforced by using a VR application (Valdez et al. 2015), the main point of which was online laboratories designed, developed and made available to students, who could access them remotely using VR. In that environment students can safely perform simple electronic laboratory experiments using relevant virtual tools, instruments, components and apparatus. Utilizing such virtual scenarios in combination with other study materials allows students to learn and participate in the education process remotely. As an added value, it eliminates risk of potentially damaging experimental strategies and minimises costs and teachers' time burden.

In Żywicki et al. (2017) the authors address the concept of Industry 4.0 and provide a system for exploring the inner operations of an intelligent factory. The system delivers a VR-space, where employees / operators of a production system can experiment with the production cycle, which allows them to make mistakes and later learn from them without real-world consequences.

However, VR systems have much more potential and some possible development is presented in Hurtado et al. (2010), where a tool for robotics education and training is introduced. Not only does it utilize visual stimuli, but it additionally includes haptic feedback interaction and a built-in physics engine. Robotic arms can be controlled by either a virtual pendant or programmed to follow specific instructions. A study conducted on the users of this application and students who followed traditional training materials indicate the advantage of the former ones, who prove to be better equipped for working with real robots. Further investigation of such an approach and homogenous results have been presented in Santos et al. (2017) and Román-Ibá nez et al. (2018). 


\section{Method}

\subsection{Project Overview}

Virtual Mechatronics Laboratory (ViMeLa) project has been created to facilitate study programs by using a state-of-the-art VR-based application developed specifically with the aim of teaching and learning mechatronics in tertiary education institutions. It is being developed in cooperation between Lodz University of Technology, Ss. Cyril and Methodius University of Skopje, University of Tartu and University of Pavia. All the partnering universities have vast background in the fields of mechatronics and IT, experts from both fields cooperate during the implementation of the project. One of the main assumptions of ViMeLa is to deliver VR space where students can experiment with machinery and are allowed to make mistakes and learn from them without real-world consequences (i.e. damaging expensive machinery). Moreover, the VR based tool will reduce the costs of introducing the latest equipment into the curriculum by removing the necessity of purchasing new machinery, by presenting models of selected equipment in VR. To develop the virtual environment of the prototype Unity3D - Game Engine is used. 3DSMax was used to design and develop all of the necessary virtual objects for the virtual scenes. Most objects are prepared as low poly models, using normal and height maps. This consequentially makes the project easily portable to other platforms. Particular stages of building the system are presented in Fig. 1.

\subsection{User Interface}

The user interface (UI), in human-computer interaction, is the environment where the interaction between human and machine occurs. The aim of UI is to allow ergonomic, effective and efficient control of the machine. The design of the user interface is an integral part for the intended user experience. It is the main part of the scenario the user interacts with and gets feedback from. With this in mind we put a lot of effort into designing the user-interface from the ground up so that it fits with a engineering style while providing enough information to be engaging. The main aspects we opted for in our design were large and simplistic UI elements, intuitive colors, and clutter minimization while still trying to maintain an attractive and appropriate look. The limitation for the amount of text was

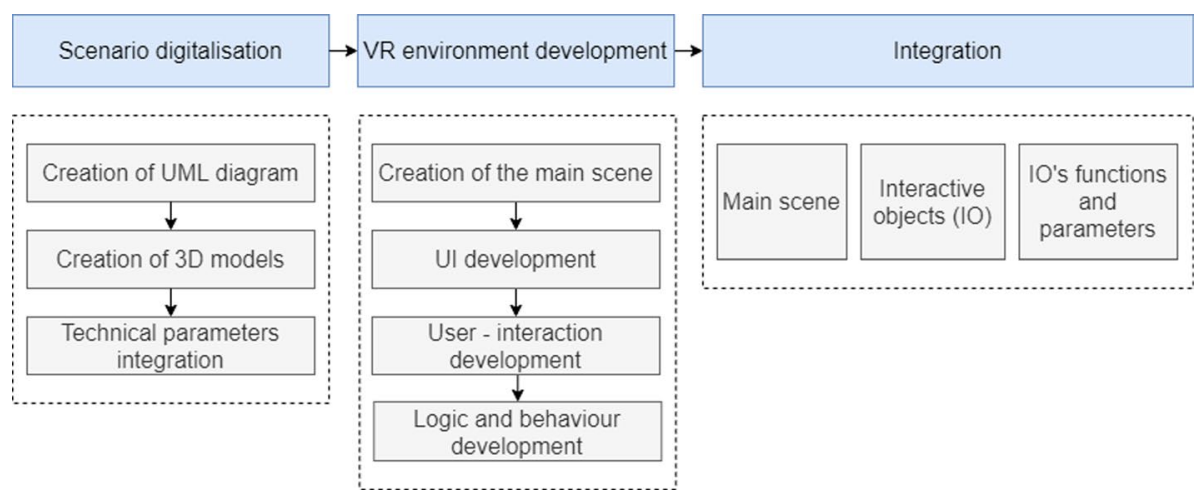

Fig. 1 Stages of creating the VR training application 


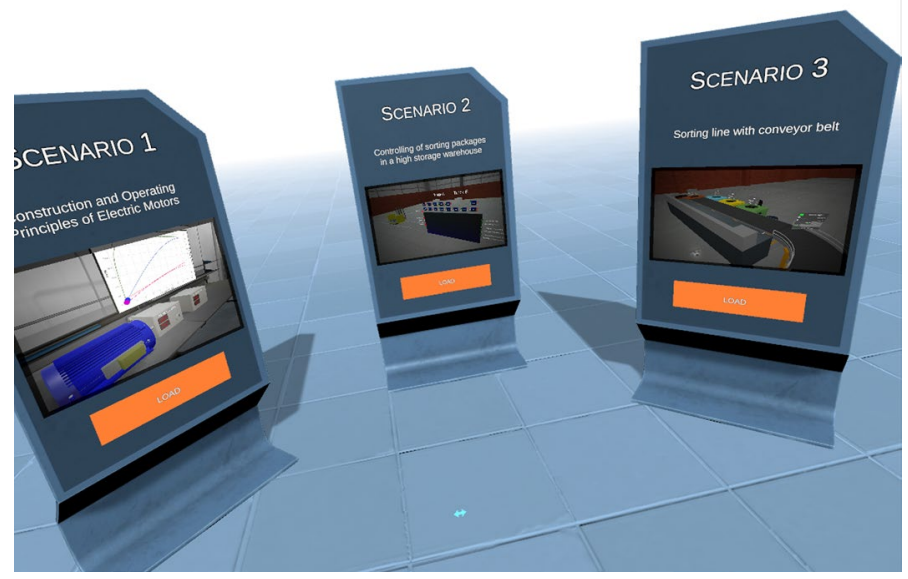

Fig. 2 The virtual user interface

apparent already in early stages of development but the key was to still keep the information in the menus comprehensible. We solved this by using standard keywords for mechanical elements and physical properties, while leaving out all descriptions which were longer than 10 letters. For buttons and sliders alike we set the sizes as large as possible, up to $\frac{1}{3}$ of the entire menu in some cases. This made it easier to physically select the menu options from a greater distance and made it easier to fine tune some values. A screenshot of the developed user interface can be seen in Fig. 2.

\subsection{Scenario}

The exercise consists of two parts: construction of pre-defined various types of electrical machines and demonstrating operating principles and performance of permanent magnet motors. The first part is dedicated to presenting the construction process and structural differences of various electrical machines such as permanent magnet synchronous motor (see Fig. 3), induction motor, switched reluctance motor, wound stator DC commutator motor, permanent magnet DC motor and permanent magnet generator.

The aim of the second part is to get the student familiar with operating characteristics and performance of above mentioned electric motors. 3D models are designed based on

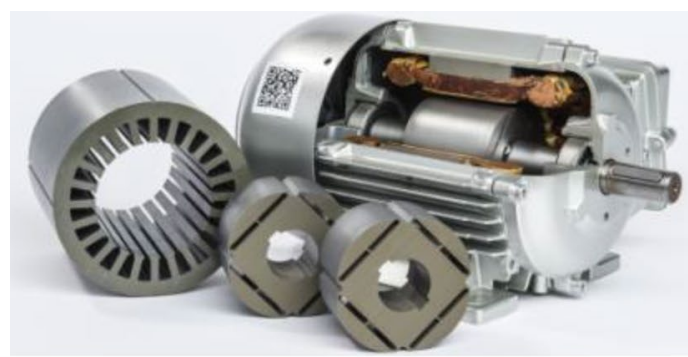

(a)

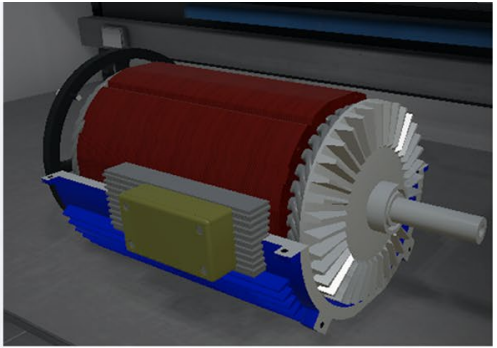

(b)

Fig. 3 Permanent magnet synchronous motor (PMSM)) a authentic machine b 3D model in VR 


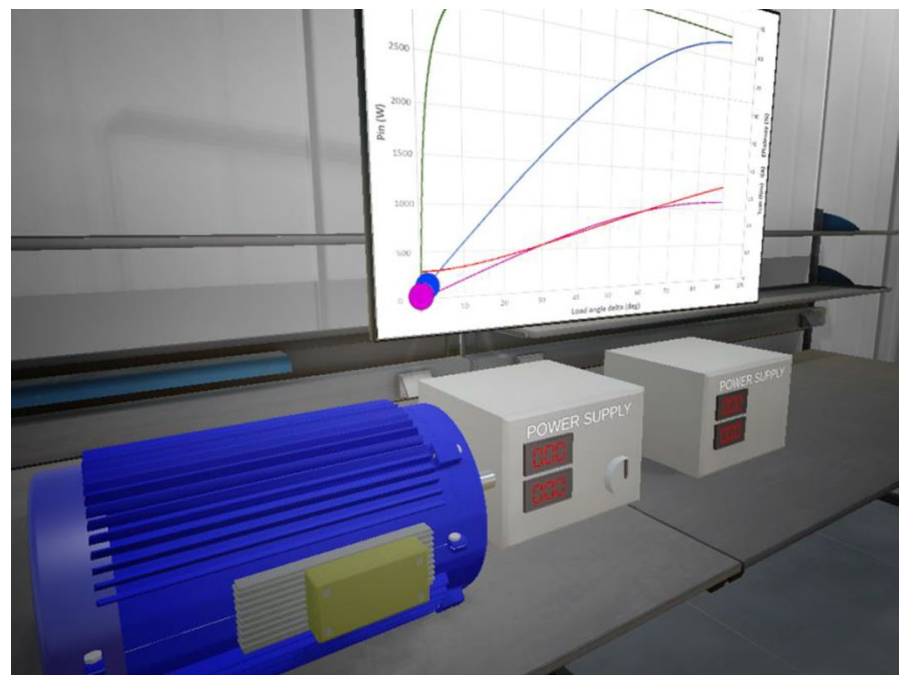

Fig. 4 View of the test bench: investigated motor connected to the testing equipment

authentic devices according to their technical documentation. The application enables virtual assembly and disassembly of individual elements of a motor (i.e. permanent magnets, windings, stator core, rotor core, shaft, bearings, housings, etc.). The simulation module presents the principles of the machines used in mechatronics systems. Virtual models enable to analyze the impact of supply conditions (i.e. values of voltage and frequency) on the work of a particular motor (Fig. 4).

The virtual environment and third-plane sound effects ensure high separation from reality. This makes students feel as if they were in one of the departments of the large factory hall with a stand representing the final stage in the process of production and distribution of electric motors (see Fig. 5). All parts for individual motors are placed on the shelves, but the number and type of required parts for assembling a specific type of motor is usually

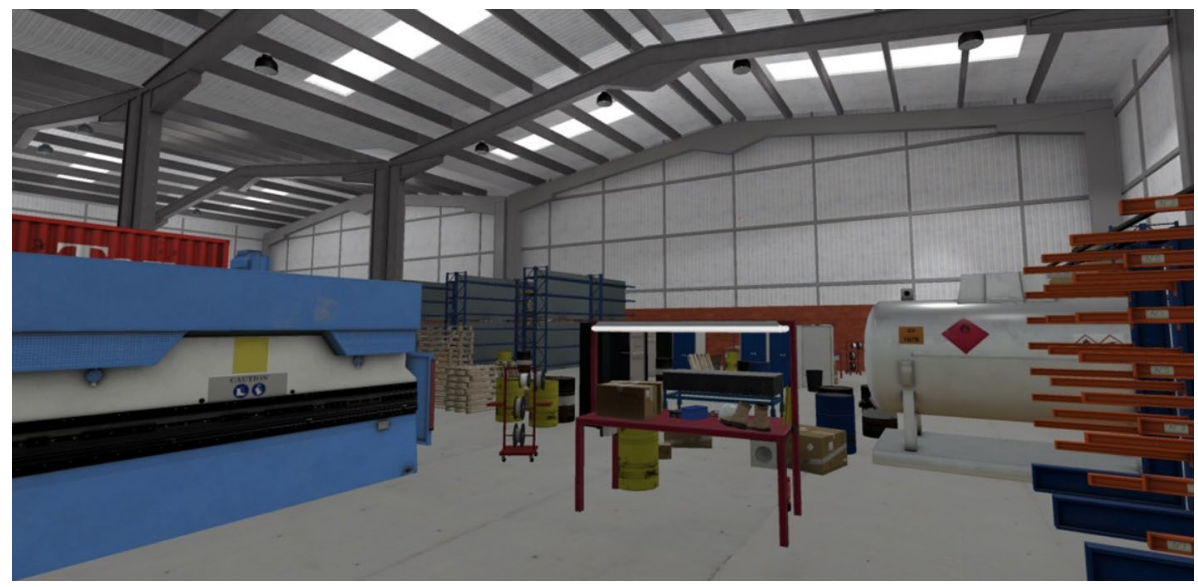

Fig. 5 Factory hall-the overall VR environment in ViMeLa project 


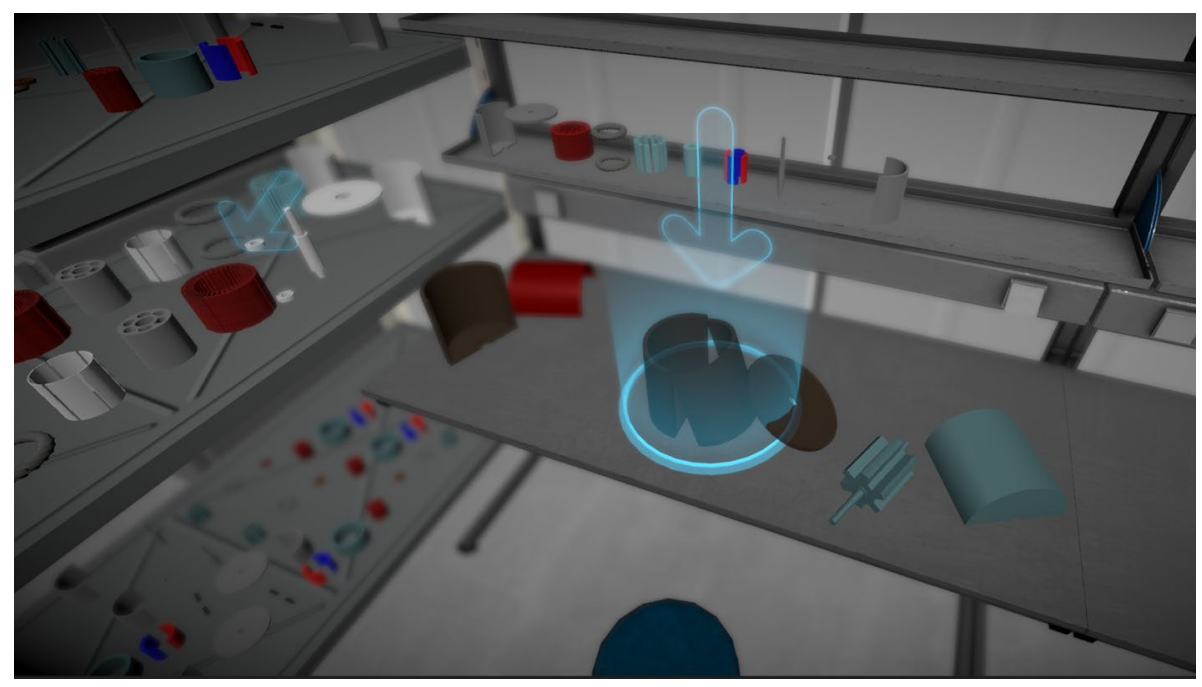

Fig. 6 The working environment - the the process of production and distribution of electric motors

different and depends on the particular machine. All elements have a specific correct position depending on the machine (see Fig. 6). For example, in case of permanent magnets, the task is to select the correct order N-S-N-S etc. All parts are fully removable, allowing the user to retract the process in case of a mistake. Wrong assembly is indicated at the end of a trial and gives the user an option to retry the task. The user gets the information whether the construction is correct or not at the end of each trial. The second part of the scenario is available only to those users that successfully pass the first part. During the second part of the exercise the user is able to perform various investigations of working principles of different motors. The user has to put a tested motor on the testing bench and make appropriate connections with the power supply, control and relevant instrumentation. If the connections are done correctly, the user can perform the investigation of operating characteristics of the motor at different working conditions. The measured values such as voltage, frequency, input current, input power, speed and torque are presented on a display. The VR environment enables the user to perform even more hazardous investigation of the motor, such as overloading it, which will be signalized as problematic working conditions. The first part of the scenario is summarized by a UML diagram presented in Fig. 7.

\subsection{Testing}

This study was carried out in the Lodz Virtual Reality Training Laboratory. The application was tested using System Usability Questionnaire (SUQ) by a group of 72 students and 24 academics. The subjects were divided into two groups by profession: the reason of these specific groups is the level of proficiency in mechatronics. All subjects provided written informed consent before testing.

On average, students were 22.17 years old (median $=22.5$, std $=1.82$, range $=19-24$ ) and the group comprised men (mean $=22.71$, median $=23$, std $=1.28$, range $=21-24)$ and women $($ mean $=21.4$, median $=20$, std $=2.15$, range $=19-24)$. On average, academics 


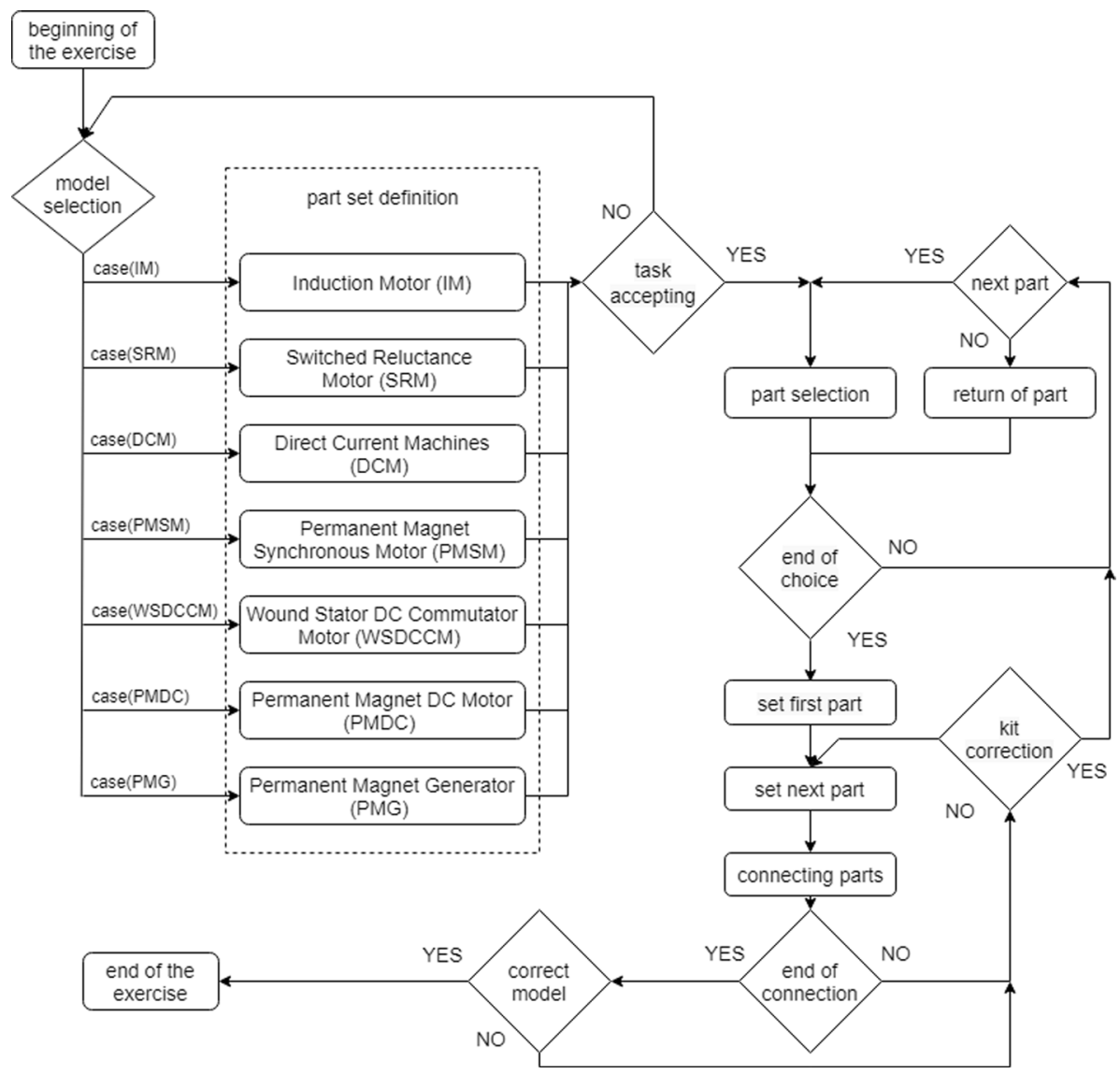

Fig. 7 UML diagram presenting the first part of VR training scenario

were 41.5 years old (median $=41$, std $=8.51$, range $=29-60)$ and the group comprised men $($ mean $=42.07$, median $=41.5$, std $=9.25$, range $=29-60)$ and women $($ mean $=39.3$; median $=38.5$, std $=6.75$, range $=28-50$ ).

The subjects with no previous experience with VR were presented with a introductory VR simulation prior to the test. Each test was performed individually, during a single session in a separate room (see Fig. 8). The subject was positioned at the center of the room and asked to put on the VR headset. When the subject was comfortable with the environment, the session was started. During one session the subject was supposed to use all available functions and go through each of the available exercises. Then, the subject was directed to another room for an interview. The participants were asked to score 10 items (see Table 1) with one of five responses that range from Strongly Agree to Strongly disagree.

Apart from evaluating application quality, assessment of quality of educational values themselves was conducted. The study was divided into two parts: a subjective part (student's assessment, see Table 3) and an objective one (evaluating the knowledge acquired while using the application and comparing it with the knowledge acquired during a traditional auditory laboratory class.) Only the students who took part in application testing 
Table 1 SUS questionnaire. The response scales use anchors such as $1=$ Strongly Disagree, $2=$ Disagree, $3=$ Neutral, $4=$ Agree, $5=$ Strongly Agree

\begin{tabular}{lllll}
\hline No & Question & & Academics & Students \\
\hline q1 & I felt very comfortable during the session & Mean & 4.54 & 4.22 \\
q2 & Nothing bothered / interrupt the immersion & SD & 0.58 & 0.71 \\
& & Mean & 4.00 & 3.9 \\
q3 & I found the visual part of VR environment realistic & SD & 0.65 & 0.93 \\
& & Mean & 4.21 & 3.78 \\
q4 & I do not feel eye strain & SD & 0.76 & 0.99 \\
& & Mean & 4.63 & 4.44 \\
q5 & I do not feel discomfort & SD & 0.75 & 0.90 \\
& & Mean & 4.04 & 4.08 \\
q6 & I would imagine that I would use VR on daily basis & SD & 0.84 & 0.99 \\
& & Mean & 2.83 & 3.92 \\
q7 & I find VR presentation useful for memorization & SD & 0.69 & 1.22 \\
& & Mean & 4.54 & 4.21 \\
q8 & I find VR presentation useful for understanding & SD & 0.58 & 0.85 \\
& & Mean & 4.63 & 4.36
\end{tabular}

participated in the first part of the study. The second part was conducted among students who tested the VR application and a control group (45 students) who only sat in an auditory laboratory session. The division of students into groups was random. Before their sessions, both groups took a pretest regarding their knowledge of electric machines, which was the subject of a prepared didactic course. Then, one group took part in a VR session, while the other participated in a traditional laboratory. After 3 days, without prior announcement, a post-test was conducted. Questions included in the pre- and post-tests are presented in Table 2.

\section{Results}

\subsection{System Usability Testing}

Initial experiments indicate that most elements of the application and the experience are evaluated positively by the final users. The results of SUS questionnaire are presented in Table 1, Fig. 9 and Fig. 10 for students and academics respectively.

Most students appreciated the opportunity offered by VR in education and would like to use VR as a part of classes (94.4\%), finding this kind of presentation useful for memorisation $(80.5 \%)$ and understanding $(83.3 \%) .83 .3 \%$ of them felt comfortable during the session. Only $6.9 \%$ of the students indicated some discomfort during the session, $5.6 \%$ felt eye strain. Most of them would imagine to use VR on a daily basis (84.7\%). Solely in case 
Table 2 Pre- and post- test questions

Circle the structural components of a permanent magnet synchronous motor?

Commutator, Squirrel cage rotor, Permanent magnets on rotor, Laminated stator core with slots, Shaft, Laminated rotor core, Silent pole stator, Concentrated winding, Distributed three phase winding, Slip rings, Rotor bars, Short circuit end rings, Bearings, Housing

Circle the structural components of an induction motor?

Distributed three phase winding, Permanent magnets on rotor, Shaf, Bearings, Commutator, Rotor bar, Brushes, Rotor shorting rings, Laminated stator core with slots, Housing, Concentrated windings

Circle the structural components of a switched reluctance motor?

Permanent magnets on rotor, Commutator, Squirrel cage rotor, Shaft, Silent pole stator, Concentrated stator winding, Distributed three phase winding, Slip rings, Rotor bars, Rotor shorting rings, Bearings, Housing, Massive stator back iron, Brushes, Silent pole rotor, Concentrated rotor winding

Circle the structural components of a permanent magnet DC motor?

Commutator, Squirrel cage rotor, Brushes, Permanent magnets on rotor, Laminated stator core with slots, Shaft, Laminated rotor core with slots, Distributed rotor winding, Permanent magnets on stator, Concentrated winding, Distributed three phase winding, Slip rings, Rotor bars, Short circuit end rings, Bearings, Housing, Shaft, Massive stator back iron

Circle the structural components of a permanent magnet synchronous generator?

Slip rings, Squirrel cage rotor, Permanent magnets on rotor, Laminated stator core with slots, Shaft, Laminated rotor core, Silent pole stator, Concentrated winding, Distributed three phase winding, Slip rings, Rotor bars, Short circuit end rings, Bearings, Housing, Commutator, Silent pole rotor

Circle the structural components of a wound stator DC commutator motor?

Commutator, Squirrel cage rotor, Permanent magnets on rotor, Massive stator core with silent poles, Shaft, Distributed rotor winding, Laminated rotor core with slots, Permanent magnets on stator, Concentrated winding, Distributed three phase winding, Slip rings, Rotor bars, Short circuit end rings, Bearings, Housing, Massive stator back iron, Brushes, Housing, Shaft, Silent pole rotor

If you have to test a three-phase permanent magnet synchronous motor whose stator winding is connected in Y (star) connection how many wires you have to use to connect the motor to the power supply?

(a) 5, (b) 3, (c) 4, (d) 2 .

What happens to rotor speed when the mechanical load on permanent magnet synchronous motor is increased?

(a) The speed increases, (b) The speed decreases, (c) The speed stays the same When the mechanical load on the permanent magnet synchronous motor is increased the load angle:

(a) Increases, (b) Stays the same, (c) Decreases

What is the maximum load (for what load angle) that can be applied to the motor shaft at which the motor will stop?

(a) 22.50 , (b) $50 \mathrm{o}$, (c) $90 \mathrm{o}$, (d) 750 ,

of question three (I found the visual part of VR environment realistic) and nine (The presented device seem real), which are both concentrated on the realism of the experience, score of 4 and 3 prevails in the assessment.

The obtained results are slightly better for academics than students. Most of the answers are positive, only in case of question two, three and six there were some disagree responses and there were no strongly disagree responses. In contrast to students, academics pointed out some discomfort during the session. This question has the largest number of neutral $(62.5 \%)$ and disagree (20.8\%) responses. Possible adverse effects might include eye strain or fatigue resulting from focusing sight on an object in immediate vicinity producing a lot of blue light. It also must be noted that during the session users have to wear a headset and often engage all their extremities. Heavy VR headset may increase the neck strain and extending the arm straight out (during selection of particular machines parts) may cause 


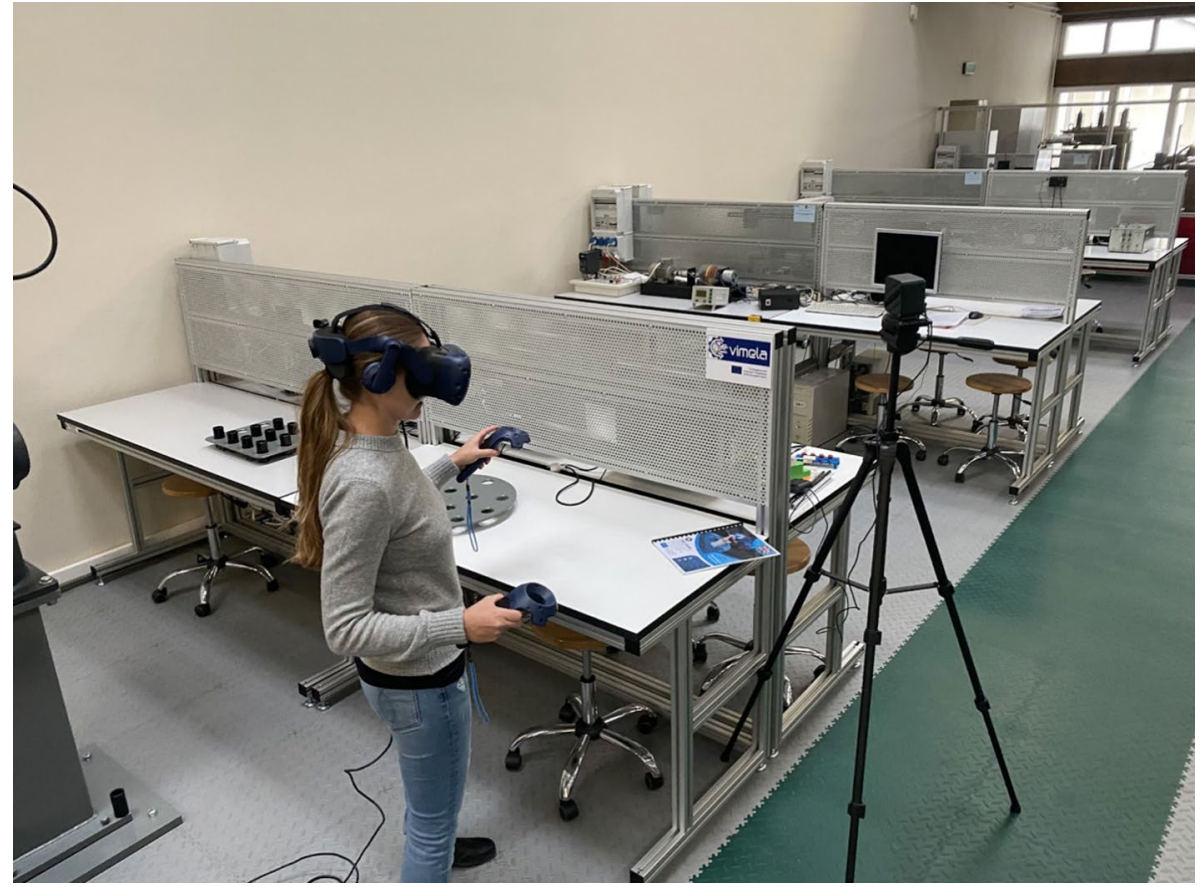

Fig. 8 Student testing the VR training application

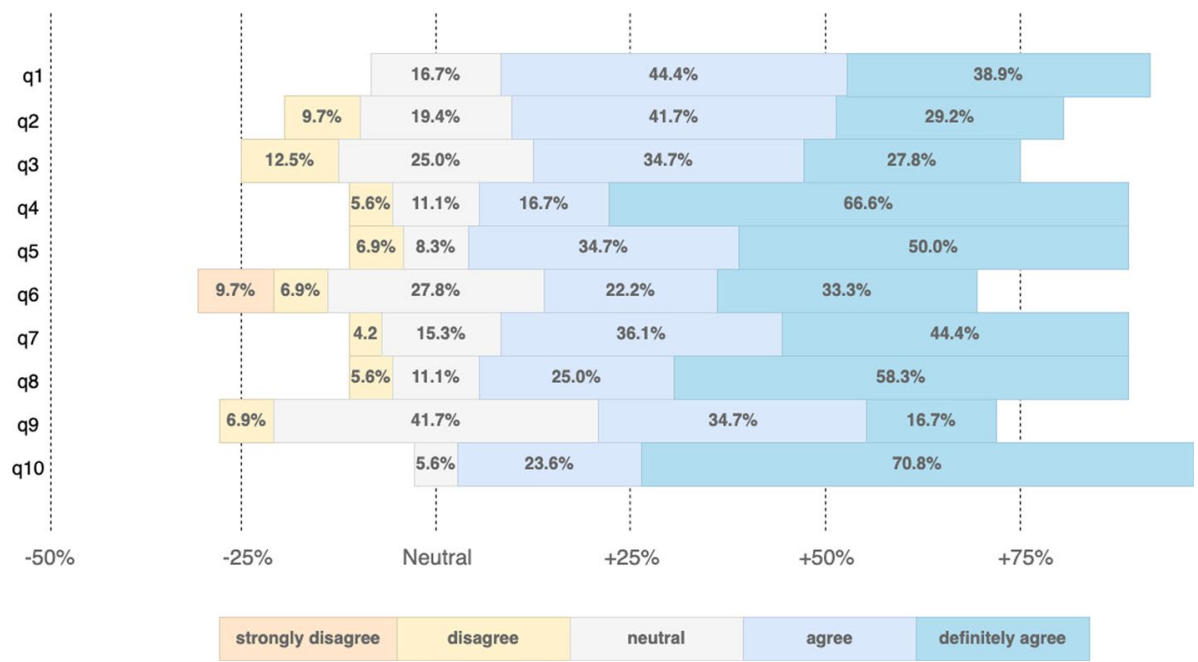

Fig. 9 Results of SUS questionnaire for the group of students

shoulder discomfort. Thus, it is very important to follow some baseline of optimal object placement and angles (for example presented in Penumudi and Kuppam (2020)) to design applications that minimize user discomfort. Additionally, the discomfort stemmed from uneasiness connected with the need to move around the virtual room, at the same time 


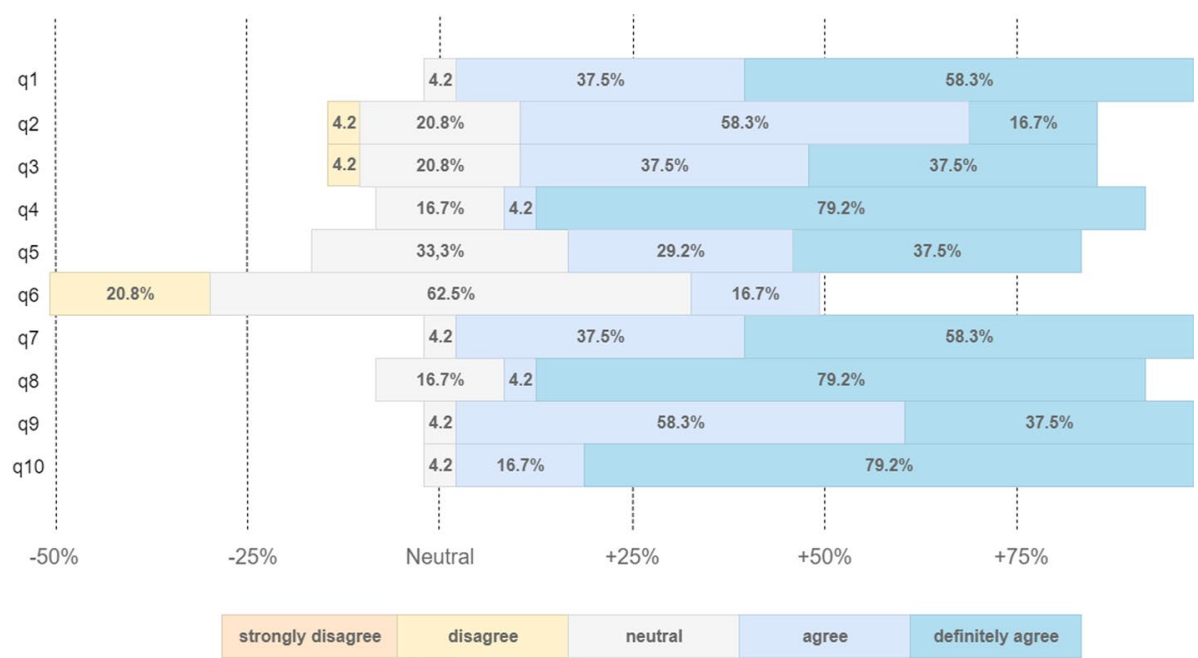

Fig. 10 Results of SUS questionnaire for the group of academics

Table 3 Subjective assessment of educational values of VR application

\begin{tabular}{lcc}
\hline Questions & Mean & STD \\
\hline $\begin{array}{l}\text { \#1 The exercise allowed me to understand the fundamentals of the basic structural part of } \\
\text { electrical machines }\end{array}$ & 4.28 & 3.28 \\
\#2 The sequence of actions for assembling the electrical machines was logical & 3.94 & 4.57 \\
\#3 Performed actions gave predictable results & 4.72 & 4.76 \\
\#4 All performed actions were relevant and necessary & 3.67 & 3.61 \\
\#5 The exercise has added value in comparison to real-world practice & 4.71 & 4.55 \\
\#6 The exercise can be used instead of real-world practice & 3,85 & 3,05 \\
\#7 The exercise allowed me to understand the fundamentals of testing of electric motors & 3.60 & 3.46 \\
\#8 The sequence of actions for preparation of the test bed for measurements was logical & 3.82 & 2.76 \\
\#9 All actions were quite realistic and close to real lab testing & 3.17 & 5.64 \\
\#10 Would you like to use this VR approach latter in other courses? & 4.61 & 4.28 \\
\hline
\end{tabular}

being unaware of the real life circumstances. A cable which is necessary in case of HTC Vive is somewhat problematic and can cause negative feelings. In practice, students had to work in pairs and while one person was immersing themselves in the VR environment, the second one was securing them. To resolve this issue, wireless autonomic solutions can be used, although it is at this moment connected with a decrease in image quality. The following are the results of the additional open question: "Give your feedback about the VR application and suggest any improvements". 63 students and 20 academics expressed that the VR training system was extremely interesting and valuable in the sense of education. Most participants told us the system is easy to use and all requirements for the user are smooth and understandable. Five students and 2 academics told us that we should improve the VR training system to make it more understandable and clear. Several participants noted the ambiguous questionnaire statement (question six). It may be caused by incorrectly asked question, which could be understood twofold: from a perspective of a 


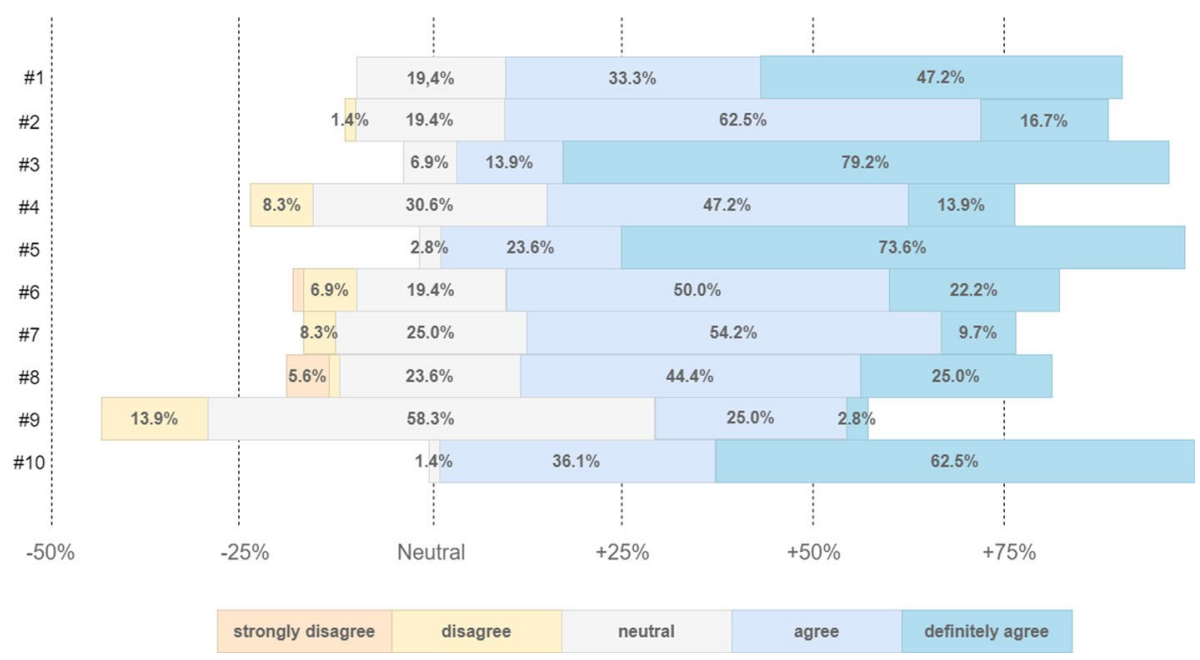

Fig. 11 Subjective assessment of educational values of VR application

user already owning a VR headset or as a person who needs to buy it (expense). Thus, we recommend to create questionnaires using more homogeneous questions to avoid ambiguous understanding (Fig. 11).

\subsection{Assessment of Educational Values}

Students' feedback contained information that performed activity allowed them to understand the basics of electric machines construction. Most of them assessed that this solution constitutes an additional value to traditional classes and would like to use it during other courses. Similarly to SUS evaluation, the worst assessed point was realism of the activity, although that had been expected. During the realisation of the project, we conducted consultations with electric machines didactic teams at partner universities. They remarked that based on their experience, better educational effects are achieved when electric machine components are clearly highlighted with unnatural colours. That is why photorealism of the VR machines was purposefully distorted.

Analysing pre- and post-tests results (Fig. 12) it can be noticed that both VR and traditional auditory laboratory have a positive effect on the knowledge of the subject (before the pretest students had only read a manual). The post-test conducted after 3 days of education indicates an advantage of VR laboratory over the traditional approach-students participating in the VR sessions passed the test $25,1 \%$ better. It is especially visible in case of six first questions regarding construction of electric machines. In VR, students had an opportunity to assemble and disassemble machines, see every part and inspect them in the context of the whole machine. Auditory classes give no such possibility (e.g. taking out windings from a rotor). What is more, free comments from students allow us to suspect that classes utilizing attractive VR didactic methods are more memorable than traditional ones. 


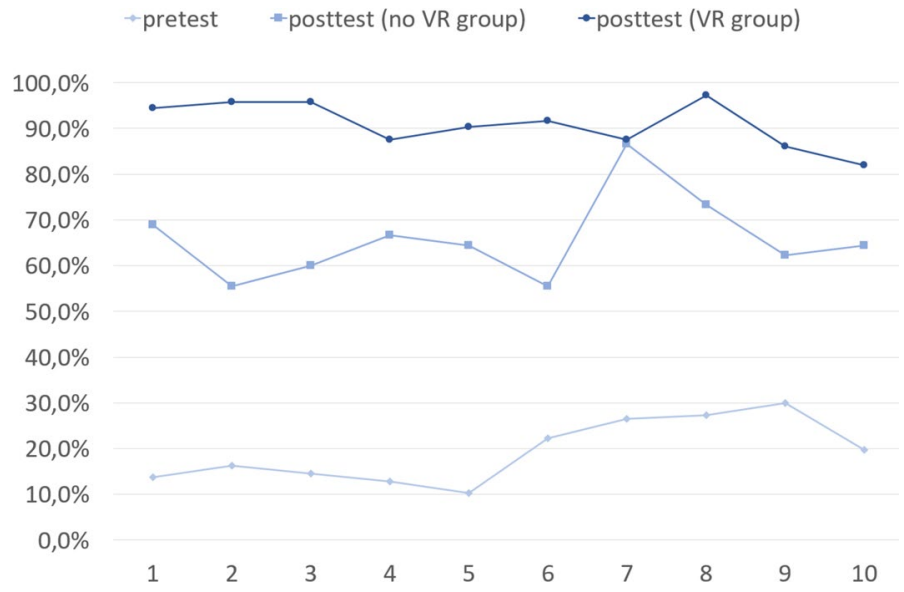

Fig. 12 Objective assessment of VR application educational values

\section{Conclusion}

In this study, an interactive VR environment was developed to demonstrate that VR may serve as a relevant asset to the mechanical and electrical laboratory. Most participants without prior training could easily interact with the platform and complete all indicated exercises. Data collected from short surveys (subjective assessment) as well as pre- and post- tests (objective assessment) shows that VR can be useful for improving the understanding and memorization process. The answers to questions concerning lack of realism are the most disturbing. Due to its psycho-visual construction, the human brain can detect even minute unrealistic elements, which immediately ruin the immersive experience. Thus, perfecting the illusion of reality in created VR worlds is an ongoing challenge. In the next version we are going to consider combining the visual part with the auditory and haptic cues to create more realistic experience.

Future works may include adding a continuous screening of heart rate, EEG and GSR signals to control the level of stress, confident and engagement of students using VR for learning as well as while solving post-tests. What is more, we would like to analyse a trajectory of movements to evaluate dexterity in the process of interaction with the platform.

From the technical side, further development of this project would have to take into consideration utilizing additional devices and functions to make the prototype a complete mechanical and electrical laboratory tool. To make the application more useful in a practical setting it would be necessary to make it available for multiple VR platforms. By doing so the application can be used on smaller and less expensive devices making the application portable (remote learning) and more attractive from an economical point of view.

Acknowledgements This publication has been co-funded by the Erasmus+ Programme of the European Union (Strategic Partnership, ViMeLa, 2017-1-PL01-KA203-038675). This publication reflects the views only of the authors, the National Agency and European Commission cannot be held responsible for any use, which may be made of the information contained therein.

Open Access This article is licensed under a Creative Commons Attribution 4.0 International License, which permits use, sharing, adaptation, distribution and reproduction in any medium or format, as long as you give appropriate credit to the original author(s) and the source, provide a link to the Creative Commons licence, and indicate if changes were made. The images or other third party material in this article 
are included in the article's Creative Commons licence, unless indicated otherwise in a credit line to the material. If material is not included in the article's Creative Commons licence and your intended use is not permitted by statutory regulation or exceeds the permitted use, you will need to obtain permission directly from the copyright holder. To view a copy of this licence, visit http://creativecommons.org/licenses/by/4.0/.

\section{References}

Achuthan, K., Sreelatha, K., Surendran, S., Diwakar, S., Nedungadi, P., Humphreys, S., CO, S.S., Pillai, Z., Raman, R. \& Deepthi, A., et al., (2011). In 2011 IEEE Global humanitarian technology conference (IEEE), pp. 117-121.

Chapman, S.M., Soto, J., Patel, M., Popp, J., \& Agyemang, C. (2019). Directed wind effect for ar/vr experience. US Patent App. 15/854,714

Courts, B., \& Tucker, J. (2012). Using technology to create a dynamic classroom experience. Journal of College Teaching \& Learning (TLC), 9(2), 121-128.

Cvetkovski, G., Petkovska, L., Di Barba, P., Mognaschi, M. E., Kamińska, D., Firych-Nowacka, A., Wiak, S., et al. (2019). ViMeLa Project: An innovative concept for teaching mechatronics using virtual reality. Przeglad Elektrotechniczny. https://doi.org/10.15199/48.2019.05.05.

Dinis, F.M., Guimar aes, A.S., Carvalho, B.R., \& Martins, J.P.P. (2017). In Global engineering education conference (EDUCON), 2017 IEEE (IEEE), pp. 1195-1202.

Dinis, F.M., Guimar aes, A.S., Carvalho, B.R., \& Martins, J.P.P. (2017). In Global engineering education conference (EDUCON), 2017 IEEE (IEEE), pp. 1683-1688.

dos Santos, M.C.C., Sangalli, V.A., \& Pinho, M.S. (2017). In Computer software and applications conference (COMPSAC), 2017 IEEE 41st Annual, vol. 1 (IEEE), vol. 1, pp. 448-455.

Gandhi, R. D., \& Patel, D. S. (2018). Virtual reality-opportunities and challenges. Virtual Reality, 5(1), 482-490.

Hurtado, C.V., Valerio, A.R., \& Sanchez, L.R. (2010). In 2010 Electronics, Robotics and automotive mechanics conference (IEEE), pp. 162-167.

Kreimeier, J., Hammer, S., Friedmann, D., Karg, P., Bühner, C., Bankel, L. \& Götzelmann, T.(2019). In Proceedings of the 12th ACM international conference on PErvasive technologies related to assistive environments (ACM), pp. 289-298.

Makarova, I., Khabibullin, R., Belyaev, E., \& Bogateeva, A. (2015). In International conference on interactive collaborative learning (ICL), 2015 (IEEE), pp. 536-544.

Mirelman, A., Rochester, L., Maidan, I., Del Din, S., Alcock, L., Nieuwhof, F., et al. (2016). Addition of a non-immersive virtual reality component to treadmill training to reduce fall risk in older adults (V-TIME): a randomised controlled trial. The Lancet, 388(10050), 1170-1182.

Müller, D., \& Ferreira, J.M. (2003). In Proceedings of the technology enhanced learning international conference (TEL O3).

Nadan, T., Alexandrov, V., Jamieson, R., \& Watson, K. (2011). Is virtual reality a memorable experience in an educational context? International Journal of Emerging Technologies in Learning (IJET), 6(1), 53-57.

Pantelidis, V. S. (1997). Virtual reality and engineering education. Computer Applications in Engineering Education, 5(1), 3-12.

Park, K.C. (2019). Haptic gloves and surgical robot systems. US Patent 10,292,780

Penumudi, S. A., Kuppam, V. A., Kim, J. H., \& Hwang, J. (2020). The effects of target location on musculoskeletal load, task performance, and subjective discomfort during virtual reality interactions. Applied Ergonomics, 84, 103010. https://doi.org/10.1016/j.apergo.2019.103010.

Qidwai, U., Ajimsha, M., \& Shakir, M. (2019). The role of EEG and EMG combined virtual reality gaming system in facial palsy rehabilitation-a case report. Journal of bodywork and movement therapies, 23(2), 425-431.

Román-Ibánez, V., Pujol-López, F. A., Mora-Mora, H., Pertegal-Felices, M. L., \& Jimeno-Morenilla, A. (2018). A low-cost immersive virtual reality system for teaching robotic manipulators programming sustainability. 10(4), 1102.

Sampaio, A.Z., Martins, O. (2017). In Proceedings of the virtual reality international conference-laval virtual 2017 (ACM), p. 21.

Servick, K. (2019). Humans may sense earth's magnetic field. Science, 63(6433), 1257-1258.

Sulbaran, T., \& Baker, N.C. (2000). In Frontiers in education conference, 2000. FIE 2000. 30th Annual, vol. 2 (IEEE), vol. 2, pp. S1D-13. 
Suzuki, M., \& Matsuura, A. (2019). In Virtual reality international conferencE VRIC 2019 proceedings, p. 39.

Valdez, M.T., Ferreira, C.M., Martins, M.J.M., \& Barbosa, F.M. (2015). In 2015 International conference on information technology based higher education and training (ITHET) (IEEE), pp. 1-4

Wang, C. X., Hilburn, I. A., Wu, D. A., Mizuhara, Y., Cousté, C. P., Abrahams, J. N., et al. (2019). Transduction of the geomagnetic field as evidenced from alpha-band activity in the human brain. eneuro. https://doi.org/10.1523/ENEURO.0483-18.2019.

Wechsler, T. F., Bahr, L. M., \& Mühlberger, A. (2019). Can gaze behavior predict stress response and coping during acute psychosocial stress - a Virtual Reality based eye tracking study. Nursing, 20(5), 697-706.

Zavalani, O., \& Spahiu, A. (2012). In 15th International conference on interactive collaborative learning (ICL), 2012 (IEEE), pp. 1-4.

Żywicki, K., Zawadzki, P., \& Górski, F. (2017). In International conference on intelligent systems in production engineering and maintenance (Springer), pp. 450-458.

Publisher's Note Springer Nature remains neutral with regard to jurisdictional claims in published maps and institutional affiliations. 